\title{
Ceramic photocatalytic membranes for water filtration under UV
} and visible light

\author{
Chrysoula P. Athanasekou ${ }^{\mathrm{a}}$, Nikolaos G. Moustakas ${ }^{\mathrm{a}}$, Sergio Morales- \\ Torres $^{\mathrm{b}}$, Louisa M. Pastrana-Martínez ${ }^{\mathrm{b}}$, José L. Figueiredo ${ }^{\mathrm{b}}$, Joaquim L. \\ Faria $^{\mathrm{b}}$, Adrián M.T. Silva ${ }^{\mathrm{b} *}$, José M. Dona-Rodriguez ${ }^{\mathrm{c}}$, George Em. \\ Romanos $^{\mathrm{a}}$, Polycarpos Falaras ${ }^{\mathrm{a}^{*}}$
}
${ }^{a}$ Division of Physical Chemistry, Institute of Advanced Materials, Physicochemical Processes, Nanotechnology and Microsystems (IAMPPNM), NCSR Demokritos, 15310 Aghia Paraskevi, Attikis, Athens, Greece
${ }^{\mathrm{b}}$ LCM - Laboratory of Catalysis and Materials - Associate Laboratory LSRE/LCM, Faculdade de Engenharia, Universidade do Porto, Rua Dr. Roberto Frias, 4200-465 Porto, Portugal
${ }^{c}$ FEAM-Departamento de Química, Universidad de Las Palmas de Gran Canaria, Edificio Central del Parque Científico-Tecnológico de la ULPGC, Campus Universitario de Tafira, 35017 Las Palmas, Spain

*Corresponding authors:

A.M.T. Silva: e-mail. adrian@fe.up.pt; Tel. +351-22 0414908

P. Falaras: e-mail.papi@chem.demokritos.gr; Tel. +302106503644

\begin{abstract}
This work demonstrates the efficiency of a hybrid photocatalysis/ultrafiltration process to eliminate or reduce the contents of synthetic dyes in water. The process involves highly active photocatalytic ceramic ultrafiltration (UF) membranes prepared with the deposition of various photocatalysts on the external and internal (pore) surface of UF mono-channel monoliths. A main challenge consists in swapping from the conventional slurry-type photocatalytic purification technology to a novel photocatalytic membrane filtration technology, using the most prominent recently developed $\mathrm{TiO}_{2}$ based nanomaterials. With this obbective, highly hydroxylated anatase $\mathrm{TiO}_{2}$ was deposited on ceramic monoliths by applying sol-gel (dip-coating) techniques. Novel materials comprising modified $\mathrm{TiO}_{2}$ nanocrystals covered with an organic shell layer as well as partially reduced graphene oxide- $\mathrm{TiO}_{2}$ composites were synthesized and stabilized on the monoliths with the target to develop visible light responding catalytic membranes. The photocatalytic filtration experiments took place
\end{abstract}


in a patented water purification device in continuous flow conditions, using methylene blue (MB) and methyl orange (MO) as azo-dye model pollutants, under near-UV/Vis and visible light irradiation. Trying to optimize the membrane photocatalytic efficiency we have examined the impact of several parameters related to both the membrane structure and the hybrid photocatalytic/filtration process including the amount, porosity and surface area of the stabilized photocatalysts as well as the surface charge. The process parameters were mainly related to the $\mathrm{pH}$ of the stream under treatment and the type of pollutant. Furthermore, the novel hybrid process was compared to the standard nanofiltration technique in regard to the pollutant removal efficiency and total energy consumption. As a consolidated output, this work proposes a novel photocatalytic membrane, developed via stabilization of organic shell layer covered $\mathrm{TiO}_{2}$ nanostructures on the internal and external surface of ceramic monoliths, as the most efficient material to be used in hybrid photocatalytic/ultrafiltration water treatment processes.

Keywords: Ultrafiltration photocatalytic membranes; titanium dioxide; graphene oxide; azo-dye pollutants; clean water.

\section{Introduction}

Photocatalysts have been extensively used in combination with membrane processes (inorganic [1-3] or polymeric [4]), with the purpose to limit biofouling and prolong the life time of the membrane. Moreover hybrid photocatalysis-ultrafiltration membrane processes have the potential to eliminate one of the most common problems of membrane separation technologies, which is the generation of toxic condensates. In many of the aforementioned applications, photocatalysts are involved in the form of powders in aqueous suspensions [5-7], as a pre-treatment process to water feeding the membrane filtration modules, or as a post treatment stage to the retentate effluent of the membranes. In the first case, stacking and accumulation of the photocatalyst nanoparticles on the membrane surface compromises the permeate flux while in the latter case, there is the need for an additional treatment to separate and recover the photocatalyst particles from the purified retentate.

More recently, photocatalyst powders have been supported on different substrates in the form of thin layers, thus overcoming technological issues associated with separation/recovery of the catalyst particles from the liquid-phase [8-9]. However, the 
photocatalyst immobilization often results in significant loss of photoactivity, mostly due to the consequent reduction of the effective surface area [10]. Micro-, meso- and nanoporous inorganic membranes in the form of monoliths have been used as immobilization substrates. These monoliths are preferred over the conventional polymeric materials, due to their excellent thermal, chemical, and mechanical stability and the possibility of reusability [11-12]. For example, when membranes are developed via dip-coating and sol-gel techniques, a high temperature treatment is further required to transform the deposited amorphous layer into the active $\mathrm{TiO}_{2}$ anatase crystal phase. Chemical stability in terms of UV irradiation and resistance to the concomitant attack by the photogenerated hydroxyl radicals is also mandatory for the application of photocatalytic membranes in processes that combine photocatalysis and filtration. Ceramic membranes, generally, consist of a macroporous substrate that provides mechanical strength for an overlying thin active layer [13-14]. The usual way to develop the active membrane layer is the sequential dip-coating of the substrate into sols composed of different precursor materials, with particles of decreasing size, as one goes from the rough support to the active layer. The purpose of this multi-coating procedure is to eliminate substrate defects [15-16] that undermine the integrity of the active top layer.

The well-known $\mathrm{TiO}_{2}$ outstanding properties, such as high surface area, relatively low toxicity, photochemical stability, light absorption, charge transport and superior excited state lifetimes, make it the 'photocatalyst of choice' for most applications [17]. Its wide use in commercial scale is mainly due to its significant activity at room temperature, to the fact that organic pollutants are usually completely mineralized to non-toxic substances (no production of recalcitrant intermediates), to its low cost and finally to the possibility of deposition on various substrates (glass, fibers, stainless steel, inorganic materials, sand, activated carbons), allowing continuous operation/re-use. However, an inherent disadvantage of the $\mathrm{TiO}_{2}$ photocatalyst limiting its multipurpose application is its high band gap (3.2 eV for anatase crystal phase), requiring activation by UV light, which represents about $4 \%$ of the solar irradiation reaching the Earth' surface. To overcome this disadvantage, visible-light-active materials and technologies are under deployment, aiming at extending the $\mathrm{TiO}_{2}$ photoresponse into the visible region thus exploiting larger part of the solar light spectrum. Modification of $\mathrm{TiO}_{2}$ by anion or metal doping [18-20] or by the combination with carbonaceous materials like carbon nanotubes, fullerenes and 
graphene oxide has recently showed significant enhancement of the photocatalytic activity of $\mathrm{TiO}_{2}[21-22]$.

We focused our work on the development of photocatalytic membranes using not only conventional $\mathrm{UV}$-active $\mathrm{TiO}_{2}$, but also organic shell layer modified [23] and partially reduced graphene oxide-nanostructured $\mathrm{TiO}_{2}$. composites [21]. These membranes have been tested for photocatalytic organic dye removal, the discharge of which is a considerable source of non-aesthetic pollution as well as eutrophication, and can originate dangerous byproducts through oxidation, hydrolysis, or other chemical reactions taking place in the wastewater phase. A high percentage (up to $20 \%$ ) of the total world production of dyes is lost during the textile process. Textile manufacturers try to convert the traditional "money-wasting" pollution control process to a profitable operation through recycling the water phase of the waste effluent. Dye degradation has therefore received increasing attention as traditional physical techniques (adsorption on activated carbon, ultrafiltration, reverse osmosis, coagulation by chemical agents, ion exchange on synthetic adsorbent resins, etc.) only succeed in transferring the organic compounds from water to another phase, usually solid, thus creating a secondary pollution source. This secondary solid waste product requires further treatment or regeneration of the adsorbent which adds extra costs to the process. Most of the dyes are also stable towards chemical oxidation and resistant towards decolorization by conventional biochemical and physicochemical methods. In real industrial effluents (i.e. of textile industry), salts exist in water together with dyes and many of the recent investigations in the field involving nanofiltration (NF) include the effect of salt concentration on the membrane surface charge and dye rejection efficiency. In the current work, we have applied solely deionized (DI) water as the liquid matrix for the MO and MB pollutants in order to study and validate the visible light photocatalytic efficiency of the membranes without any interference from parameters related to the overall water quality. Taking into account the UF character of the modified $\mathrm{N}-\mathrm{TiO}_{2}$ membranes, solute rejection due to size or Donnan exclusion are not the dominant mechanisms of pollutants removal and consequently, the effect of dissolved salts can be neglected.

\section{Experimental}

\subsection{Materials and reagents}


The photocatalysts were developed on $\gamma$-alumina UF tubular membrane substrates (mono-channel monoliths) possessing glazed ends of $1.5 \mathrm{~cm}$ length each. The membranes were provided by Fraunhofer IKTS (Fraunhofer Institute for Ceramic Technologies and Systems, Germany) under the commercial name of Inopor®. They presented nominal pore size of 10nm, and had a length of $15 \mathrm{~cm}$, ID and OD of 7 and $10 \mathrm{~mm}$, respectively, with the ultrafiltration layer (1.5 microns in thickness) located on their internal side. In addition, two intermediate pore size $\gamma$-alumina layers and a rough macroporous $\alpha$-alumina support composed the entire mono-channel monolith. Details on the pore size and volume of the several layers can be found elsewhere [23]. For the evaluation of the photocatalytic efficiency of the membranes, Methyl Orange $\left(\mathrm{C}_{14} \mathrm{H}_{14} \mathrm{~N}_{3} \mathrm{NaO}_{3} \mathrm{~S}\right)\left(99 \%\right.$ Sigma-Aldrich) and Methylene Blue $\left(\mathrm{C}_{16} \mathrm{H}_{18} \mathrm{~N}_{3} \mathrm{SCl}\right)$ (99\% Sigma-Aldrich) were used as model water pollutants: The decomposition of the pollutants was determined using a Hitachi U-3010 UV-Visible Spectrophotometer through the decrease of the characteristic absorbance peaks of MO $\left(\lambda_{\max }=466 \mathrm{~nm}\right)$ and $\mathrm{MB}\left(\lambda_{\max }=664 \mathrm{~nm}\right)$. The concentrations of the solutions used in the photocatalytic tests ware $6.4 \mathrm{mg} / \mathrm{L}$ for the $\mathrm{MO}$ and $2 \mathrm{mg} / \mathrm{L}$ for the $\mathrm{MB}$.

\subsection{Membrane development.}

\subsubsection{Organic shell layer modified- nanostructured $\mathrm{TiO}_{2}$ membrane $\left(\mathrm{N}-\mathrm{TiO}_{2}-10\right)$}

For the preparation of the modified nanostructured $\mathrm{TiO}_{2}$ sol, $15 \mathrm{ml}$ of tetrabutyl orthotitanate (Aldrich 97\%) were added dropwise into $100 \mathrm{ml}$ of deionized $\mathrm{H}_{2} \mathrm{O}$ acidified with nitric acid (1.5ml). After vigorous stirring for 4 hours, 1-propanol (30 ml) was added and the translucent colloidal solution became completely transparent. The solution was left overnight under vigorous stirring and finally $30 \mathrm{~g}$ of Urea (Merck) were added. The, $10 \mathrm{~nm}$ pore size, $\gamma-\mathrm{Al}_{2} \mathrm{O}_{3}$ membranes were coated with the surface modified- nanostructured $\mathrm{TiO}_{2}$ using the dip-coating technique. The glazing at both ends was covered with Teflon tape and then the membrane was dipped into the sol in a vertical position following three successive dip in - pull out cycles at a rate of $15 \mathrm{~cm} \mathrm{~min}^{-1}$. Our purpose was to deposit the visible light active- $\mathrm{TiO}_{2}$ catalyst on the shell and lumen side surface of the monolith simultaneously as well as into the pores, in order to enhance the pollutants photodegradation efficiency by illuminating both membrane surfaces during a filtration process accelerated by photoinduced hydrophilicity. The membrane was heated at a low rate $\left(0.5^{\circ} \mathrm{C} / \mathrm{min}\right)$ to avoid thermal 
shock and cracking of the membrane up to $400{ }^{\circ} \mathrm{C}$, where it remained for 2 hours. The $\mathrm{N}-\mathrm{TiO}_{2}-10$ membrane was weighted before and after calcination and was found heavier by $20 \mathrm{mg}\left(0.033 \mathrm{mg} / \mathrm{cm}^{2}\right)$, due to the deposition of the $\mathrm{N}-\mathrm{TiO}_{2}$ material.

\subsubsection{Reduced graphene oxide- $\mathrm{TiO}_{2}$ composite membrane (GOT-10)}

Natural graphite (99.9995\% purity, $20 \mu \mathrm{m}$, from Sigma-Aldrich) was used as precursor of graphene oxide (GO). First, graphite oxide was prepared through the modified Hummers method [24-25]. Then, the resulting material was dispersed in a given volume of water and sonicated with an ultrasonic processor (UP400S, $24 \mathrm{kHz}$ ) for $1 \mathrm{~h}$. The resulting sonicated dispersion was centrifuged for $20 \mathrm{~min}$ at $3000 \mathrm{rpm}$ to obtain a suspension of GO. Then, the GOT composite was synthesized with these dispersions by the liquid phase deposition (LPD) method at room temperature, as described elsewhere [24]. Briefly, ammonium hexafluorotitanate (IV) $\left(\mathrm{NH}_{4}\right)_{2} \mathrm{TiF}_{6}(0.1$ mol/L) (>99.99\% Sigma-Aldrich), and boric acid $\mathrm{H}_{3} \mathrm{BO}_{3}$ (>99\% Sigma-Aldrich) (0.3 $\mathrm{mol} / \mathrm{L}$ ), were added to a certain amount of the GO dispersion heated at $60{ }^{\circ} \mathrm{C}$ for $2 \mathrm{~h}$ under vigorous stirring. The material was separated by filtration, washed with water and dried at $100^{\circ} \mathrm{C}$ under vacuum for $2 \mathrm{~h}$. The carbon loading (4 wt.\%) was selected taking into account the highest photocatalytic activity obtained with this GOT composite in our previous work [24]Error! Bookmark not defined.. $\mathrm{Bare}^{\mathrm{TiO}_{2}}$ was also prepared and treated by the same method, without the addition of any carbon material. An aqueous dispersion $(50 \mathrm{~g} / \mathrm{L})$ containing the corresponding photocatalyst (GOT or reference $\mathrm{TiO}_{2}$ material) was used to deposit the material on the different ceramic membranes by dip-coating (down/up velocity of $5 \mathrm{~cm} \mathrm{~min}^{-1}$ and dipping time of 30 seconds). Three layers were applied on the membranes and after each one, the membrane was dried at $120{ }^{\circ} \mathrm{C}$ in an oven for $30 \mathrm{~min}$. After that, the coated membranes were treated at $200{ }^{\circ} \mathrm{C}$, with a heating and cooling rate of $1{ }^{\circ} \mathrm{C} / \mathrm{min}$ and under a $\mathrm{N}_{2}$ atmosphere. During the thermal treatment, a partial reduction of GO occurs (reduced graphene oxide - $\mathrm{rGO}$ ), with anatase $\mathrm{TiO}_{2}$ particles being exclusively formed at such temperature. Finally, the ceramic membranes were softly flushed with compressed air in order to remove the particles not well-adhered before to be used in reaction. The membranes prepared with GOT and with the reference bare $\mathrm{TiO}_{2}$ material are labeled as "GOT-10" and "ref GOT-10", respectively.

\subsubsection{UV-active $\mathrm{TiO}_{2}$ membrane (ECT-10)}


For the preparation of the ECT (ethanol, citric, tetrabutoxide) $\mathrm{TiO}_{2}$ solution, an ethanol (Panreac 99.5\%)-titanium butoxide (Aldrich 97\%) solution, 50:3.5 ratio molar, was added drop by drop to a water-ethanol-citric acid (Panreac 99.5\%) solution, 50:60.8:0.36 ratio molar. The mixing time was $3 \mathrm{~h}$. After mixing, the final solution was stirred for $30 \mathrm{~min}$ and then allowed to age for $48 \mathrm{~h}$. Then, the catalysts were left to dry at $100{ }^{\circ} \mathrm{C}$ for $24 \mathrm{~h}$. More details about the material are published elsewhere [26-27]. As stated in [27], the high photocatalytic efficiency of ECT calcined at $750^{\circ} \mathrm{C}$ is related to its enhanced availability to originate reactive hydroxyl radicals from photoinduced holes at the catalyst surface. For the preparation of the ECT-10 membrane, a similar methodology to that previously described for the GOT10 and ref GOT-10 membranes was employed.

\subsection{Membrane Photocatalytic Performance evaluation}

The hybrid photocatalytic/membrane filtration process took place in a photocatalytic purification device described in detail elsewhere [28]. In brief, the purification device allowed the simultaneous performance of dead-end filtration / photocatalytic tests, with irradiation applied on both surfaces of the monochannel monolith. Near-UV radiation $(315-380 \mathrm{~nm})$ with a peak at $365 \mathrm{~nm}$, was applied for irradiating the shell side surface of the monolith at a light intensity of $2.1 \mathrm{~mW} \mathrm{~cm}^{-2}$. This irradiation density was achieved by four UV lamps of $9 \mathrm{~W}$ (Phillips-UVA (PUVA) PL-S/PL-L) placed at a distance of $3 \mathrm{~cm}$ from the outer Plexiglas cell of the membrane reactor and sleeved by a cylinder of thick aluminum foil. Four visible lamps of 9 W (Osram DULUX S 9W/21-840 G23 LUMILUX Cool White), placed at the same distance of $3 \mathrm{~cm}$ from the Plexiglas cell were used to achieve a Vis light irradiation density of $7.2 \mathrm{~mW} \mathrm{~cm} \mathrm{c}^{-2}$. The lumen side membrane surface was irradiated by means of either an array of 10 UVA miniature LED emitting near-UV radiation (360 to $420 \mathrm{~nm}$ ) with a peak at $383-392 \mathrm{~nm}$ at a light intensity of $0.5 \mathrm{~mW} \mathrm{~cm} \mathrm{~cm}^{-2}$ or an array of 6 visible SMD LEDs (OSA-Optolight OLS-336 BA460) emitting at $460 \mathrm{~nm}$ at a light intensity of $0.3 \mathrm{~mW} \mathrm{~cm}{ }^{-2}$. The total flow of polluted water feeding the reactor was $1.5 \mathrm{~mL} / \mathrm{min}$ for all the membranes and the filtration was performed in the dead-end mode. The concentration (C) of MO and MB collected from the retendate and permeate side of the membrane and the concentrations $\left(\mathrm{C}_{0}\right)$ of the feed were determined by measuring the visible light absorbance at $466 \mathrm{~nm}$ and $664 \mathrm{~nm}$ 
respectively. The total amounts of removed pollutant were obtained from the mass balance between feed and permeate. After each photocatalytic experiment, the cell unit, the piston and the fluid delivery system were washed with deionized $\mathrm{H}_{2} \mathrm{O}$ to ensure that no pollutant species remained in the photocatalytic reactor. The experiments were performed under variable photocatalytic conditions by modifying the fluid flow rate (contact time), the concentration of the pollutant, and the active irradiated surface. This was the first time that a photocatalytic filtration process exploited the action of two active surfaces in one membrane element and the overall concept and way of implementation in an efficient water purification device are already covered by a European patent [29]. Experiments with control samples (unmodified membranes) under irradiation and control experiments with modified and unmodified membranes (in the absence of irradiation), permitted the calculation of the net photocatalytic activity of the two active surfaces developed in each membrane.

\section{Results and Discussion}

\subsection{Evaluation of the sorption capacity- Filtration experiments in dark.}

Filtration experiments were performed sequentially, starting without irradiation (in dark) and the capacity of the two membranes to remove MO $\left(4.4 \times 10^{-3}\right.$ $\mathrm{mg} / \mathrm{mL}$ or $1.49 \mathrm{~mol} / \mathrm{L})$ and $\mathrm{MB}\left(1.8 \times 10^{-3} \mathrm{mg} / \mathrm{mL}\right.$ or $\left.0.58 \mathrm{~mol} / \mathrm{L}\right)$ from their aqueous solutions was examined in the dead-end filtration mode (flow-through) with a feed flow of $1.5 \mathrm{~mL} / \mathrm{min}$. The large pore size $(10 \mathrm{~nm})$ of the ultrafiltration membranes implies that the mechanisms of size exclusion and charge repulsion of the pollutant molecules should be neglected. However, concentration polarization phenomena can occur when working at the flow-through mode because of the very high water flux through the coated membranes. The thickness of the polarization layer increases as revealed by the plot presented in Figure 1a, which presents results of the filtration experiments in dark and relates the adsorbed amount of pollutant to the total amount of pollutant fed in the reactor. Filtration experiments in dark had been conducted until the amount of pollutant adsorbed by the unknown amount of the stabilized photocatalyst levels off. Batch adsorption experiments (in dark) of the respective photocatalysts in their powder form were also conducted for the determination of their maximum adsorption capacities $\left(\mathrm{mg} \cdot \mathrm{g}^{-1}\right)$ at $\mathrm{pH}$ conditions similar to the ones used in the filtration experiments. The ordinate of each point in Figure 2a was calculated by 
applying the $\mathrm{MO}$ and $\mathrm{MB}$ mass balance between the feed and permeate side of the membrane.

The adsorption capacities of the membranes, as derived from the dead-end filtration experiments with $\mathrm{MO}$ and $\mathrm{MB}$, divided by the respective adsorption capacities of the photocatalytic powders $\left(\mathrm{mg} \cdot \mathrm{g}^{-1}\right)$, gave the amount of photocatalyst which was deposited and stabilized on the ceramic substrates. This amount followed the order: mass ${ }_{(\mathrm{N}-\mathrm{TiO} 2)}>$ mass $_{(\mathrm{ECT})}>$ mass $_{(\mathrm{GOT})}>$ mass $\left._{(\mathrm{ref}} \mathrm{GOT}\right)$ in accordance with the quantities of the adsorbed pollutant as they appear in figure $2 \mathrm{~b}$. Figure $2 \mathrm{~b}$ also reveals that three of the membranes exhibited preferable adsorptivity for $\mathrm{MB}$, the organic shell layer covered $\mathrm{TiO}_{2}$ membrane being the only exception. The preferable adsorption of $\mathrm{MO}$ over $\mathrm{MB}$ on this membrane can be explained if someone considers the Point of Zero Charge $\left(\mathrm{pH}_{\mathrm{PZC}}\right)$ of the involved nanocatalysts in relation to the $\mathrm{pH}$ of the water solution and the charge of the two pollutants under these conditions. The $\mathrm{pH}$ of the used MB solution is 7.2 and the positively charged MB ions (Figure 2a), were attracted electrostatically by the strongly negative charged surfaces of the ECT-10, GOT-10 and the ref GOT-10 membranes $\left(\mathrm{pH}_{\mathrm{PZC}}(\mathrm{ECT}-10) \approx 5.2, \mathrm{pH}_{\mathrm{PZC}}(\mathrm{GOT}-10) \approx\right.$ 3.2 and $\mathrm{pH}_{\mathrm{PZC}}($ ref GOT-10) $\approx 3.5)$. On the other hand, at the $\mathrm{pH}$ conditions of the MO solution $\left(\mathrm{pH}=6.0\right.$ at a concentration of $\left.4.4 \mathrm{mg} \mathrm{L}^{-1}\right)$ the surface of the ECT-10, GOT-10 and ref GOT-10 membranes is neutral to negative while MO is also negatively charged since it has lost its amphoteric character due to deprotonation at the $-\mathrm{N}=\mathrm{N}-$ bridge between the rings. This concludes to electrostatic repulsion and limits the amount of adsorbed MO. Regarding the $\mathrm{N}_{-} \mathrm{TiO}_{2}-10$ membrane $\left(\mathrm{pH}_{\mathrm{PZC}}(\mathrm{N}-\right.$ $\left.\mathrm{TiO}_{2}\right) \approx 6.7$ ), its surface is positively charged at the $\mathrm{pH}$ conditions of the MO solution [30] and as a consequence it attracts the negatively charged MO. On the other hand it is almost neutral at the $\mathrm{pH}$ conditions of the $\mathrm{MB}$ solution and thus, this explains the higher adsorption capacity for MO compared to MB.

\subsection{Photocatalytic filtration experiments under UV irradiation}

After the completion of dye adsorption in dark, all membranes underwent UV light irradiation experiments, with the UV-light irradiation sources being applied on the lumen and the shell side surfaces of each membrane. The flow direction of the aqueous solution was from the shell to the lumen side and the respective photocatalytically active surfaces of each membrane were approximately 25 and $17.5 \mathrm{~cm}^{2}$. Figure 3 presents the amount of pollutant versus the total amount fed in the 
reactor. The slope of the treadlines fitted to the curves is characteristic for the photocatalytic efficiency of each membrane. As seen, the $\mathrm{N}-\mathrm{TiO}_{2}-10$ membrane was the most efficient, photodegrading the higher amounts of MO and MB. If comparing GOT-10 to its analog prepared with the reference $\mathrm{TiO}_{2}$ catalyst (ref GOT-10), one can see that the addition of graphene oxide to $\mathrm{TiO}_{2}$ favors significantly the degradation efficiency of the membrane for $\mathrm{MB}$, although it doesn't affect much the photodegradation efficiency of MO. ECT-10 exhibits similar effectiveness to that of the GOT-10 membrane, which, in the case of MO, does not differ much from the reference membrane (ref GOT-10). When irradiated with UV-light, all the membranes performed better against MB compared to MO. At this point we should stress issues related to the effect of the adsorption capacity on the photocatalytic efficiency of the membranes. It can be seen that the three membranes (ECT-10, GOT10 and ref GOT-10) presenting higher adsorption capacity for MB exhibited also a 2 to 5-fold higher photocatalytic efficiency for MB compared to MO. On the other hand the $\mathrm{N}-\mathrm{TiO}_{2}-10$, with higher adsorption capacity for $\mathrm{MB}$, exhibited almost similar photodegradation efficiency for both pollutants. The following Table 1 presents the photocatalytic efficiency of the membranes (slopes of the plots in Figures 3 and 4) associated with the absolute amount of $\mathrm{MO}$ and $\mathrm{MB}$ adsorbed and with the photocatalyst characteristics such as the surface area, pore volume, adsorption capacity and Point of Zero Charge ( $\left.\mathrm{pH}_{\mathrm{PZC}}\right)$.

It can be concluded that amongst the structural characteristics of the deposited photocatalysts, solely the pore volume correlates well with the photocatalytic performance of the membranes. Moreover, the photocatalytic efficiencies correlate well with the absolute amount of the adsorbed pollutant and not with the adsorption capacity $\left(\mathrm{mg} \cdot \mathrm{g}^{-1}\right)$ of each material. The latter unveils that we have achieved the transfer and stabilization of the most appropriate amounts of photocatalysts, thus generating ultra-thin deposits which were fully accessible to the incident irradiation.

\subsection{Photocatalytic filtration experiments under Vis light irradiation}

Visible light filtration experiments were also conducted on the membranes after an initial step of dye adsorption in dark. The Vis-light irradiation sources were applied on the lumen and the shell side surfaces of each membrane. The results proved encouraging for the use of organic shell layer covered nanostructured $\mathrm{TiO}_{2}$ for the development of photocatalytic membranes. In figure 4, the slope of each treadline 
corresponds to the photocatalytic efficiency of the membrane under Vis-light irradiation. As seen, $\mathrm{N}-\mathrm{TiO}_{2}-10$ exhibits photocatalytic efficiency which is 1.5 and 3 fold higher than this of the other membranes, for MB and MO, respectively, a fact attributed to its narrow band gap $(2.19 \mathrm{eV})$, which makes possible its activation under visible light. The addition of graphene oxide to titania (GOT-10) doubles the performance for the photodegradation of both pollutants under visible light illumination. The ECT-10 and N-TiO2 10 membranes exhibited almost similar photocatalytic performance in the degradation of MB under UV (Figure 3a). However, under vis-light the MB photodegradation efficiency of ECT-10 was moderate showing that the respective photocatalyst is not appropriate for applications in the visible range of the electromagnetic spectrum.

\subsection{Comparison of the membranes' performance in terms of pollutant removal efficiency and energy efficiency of the process.}

The importance of inducing photoactivity on the surface of UF membranes is evidenced by the filtration performance characteristics presented in Table 2 which includes the operation parameters of the photocatalytic filtration process and the efficiency in terms of pollutant rejection efficiency $(\mathrm{R} \%)$ and capacity to reduce the dyes' concentration $\left(C / C_{0}\right)$ at the permeate effluent.

The pollutant rejection efficiency (R\%) was calculated according to Equation 1:

\begin{tabular}{|c|c|}
\hline $\mathrm{R} \%=\frac{\mathrm{C}_{\mathrm{f}}-\mathrm{C}_{\mathrm{p}}}{\mathrm{C}_{\mathrm{f}}} \mathrm{x} 100$ & (1) \\
\hline
\end{tabular}

where $\mathrm{R} \%$, the rejection factor, $\mathrm{C}_{\mathrm{f}}$ and $\mathrm{C}_{\mathrm{p}}$, the concentration of methyl orange in the feed stream and permeate effluent of the membrane respectively.

The permeance $\left(\mathrm{L} \mathrm{m}^{-2} \mathrm{~h}^{-1}\right.$ bar $\left.^{-1}\right)$ was calculated according to Equation $2(2$

$$
\mathrm{Pe}=9.138 \times 10^{-5} \frac{\mathrm{F}_{\mathrm{w}}}{\mathrm{S} \Delta \mathrm{P}} \times \rho_{\mathrm{w}}
$$

where $F_{w}(\mathrm{ml} / \mathrm{min})$ the water flow measured at the permeate side of the membrane (inner channel), $\mathrm{S}\left(\mathrm{cm}^{2}\right)$ the active surface of the membrane, $\Delta \mathrm{P}(\mathrm{atm})$ the pressure difference between the outer and the inner channel of the reactor and $\rho w$ the density of water at the temperature of measurement.

The energy consumption $\left(\mathrm{kWh} / 100 \mathrm{~m}^{3}\right)$ was calculated by means of Equation 3, in terms of the pump power (shaft power) over the time needed to drive $100 \mathrm{~m}^{3}$ of water 
to the membrane module, overcoming in parallel the pressure drop generated on the opposite sides of the membrane during the cross flow filtration.

$$
\mathrm{E}(\mathrm{kWh})=100 \times \frac{\mathrm{P} \times \rho_{\mathrm{w}}}{\mathrm{S} \times 36}
$$

In Equation 3, P (bar) is the pressure in the retentate side of the membrane, $\rho_{\mathrm{w}}\left(\mathrm{g} / \mathrm{cm}^{3}\right)$ the density of the fluid and S the pump efficiency (usually 0.8). The performance can also be expressed in terms of pollutant concentration reduction at the permeate, $\mathrm{C} / \mathrm{Co}$.

The performance characteristics of the membranes during filtration in dark (Table 2), are reported after the establishment of steady state (adsorption has reached equilibrium). All membranes succeed better against MB than MO. When the efficiency of the membranes is evaluated in terms of their capacity to reduce the dyes concentration $\left(C / C_{0}\right)$ at the permeate effluent, the UV irradiation proves more effective than the visible one, apart from membrane $\mathrm{N}-\mathrm{TiO}_{2}-10$, where the organic layer of the nanoparticles, seems to enrich the effectiveness against MB, something that does not happen with MO possibly due to the cationic nature of MB. The best performance results come from the GOT-10 and the ECT-10 membranes, which under UV light achieve to reduce the MB concentration at the permeate effluent down to the $65 \%$ of the feed.

It can be seen (Table 2) that the permeance values increased, when the membranes were suddenly exposed from filtration in dark to UV irradiation. This is attributed to the photocatalytic degradation of the concentrated pollutant that had been accumulated on the external surface (feed surface) of the membrane, upon completion of the adsorption experiment in dark. As already mentioned, irradiation (UV or VIS) is applied to both surfaces of the tubular membrane, aiming to mitigate fouling on the external surface (nano pores) during filtration and to enhance the photoactivity on the internal surface, due to high photocatalyst mass per water volume ratio servicing the elimination of the pollutants from the permeate effluent. The enhanced permeability of the $\mathrm{N}-\mathrm{TiO}_{2}-10$ membrane when irradiated with visible light, compared to UV light, should be highlighted, since it proves the attainment of the desired activation targeted activation of the catalyst under visible light. The Ref GOT-10 proved to be the most hydrophilic material of the four types of $\mathrm{TiO}_{2}$ used, since this membrane exhibits the highest water flux properties at very low trans-membrane pressures and, therefore, the lowest energy dissipation during operation. Nevertheless, its poor dye removal performance prevents it from being a candidate for UF membrane applications. 
The highest pollutant rejection efficiency was achieved using the $\mathrm{N}-\mathrm{TiO}_{2}-10$ membrane against MB and under UV light. ECT-10 and GOT-10 come next, leaving the ref GOT-10 membrane last. The same ranking holds for MO, under both UV and Vis light. Nevertheless, when the energy expense is also considered, $\mathrm{N}^{-\mathrm{TiO}_{2}-10}$ does not appear to be the best choice. GOT-10 can provide $63 \%$ of the $\mathrm{N}^{-\mathrm{TiO}_{2}-10}$ membrane's rejection efficiency while consuming only $28 \%$ of the respective energy. This means that by recycling the permeate effluent of the GOT-10 membrane back to the reactor two or more times, we can achieve a higher $\mathrm{MB}$ or $\mathrm{MO}$ rejection efficiency value than that of $\mathrm{N}-\mathrm{TiO}_{2}-10$, with lower total energy consumption.

In any case, the energy consumption values illustrated in Table 2 are, by far, lower than the energy consumption of a typical commercially available ceramic NF membrane which consumes $85 \mathrm{kWh}$ to clean, by size exclusion, $100 \mathrm{~m}^{3}$ of polluted water, with a MO rejection efficiency of $12 \%$. A typical Reverse Osmosis system needs about $120 \mathrm{kWh}$ for the same task. The water recovery of all the photocatalytic membranes tested in this study was $100 \%$, since the experiments were taken place at the "flow through" or "dead end" mode. Contrary, the NF membrane could only participate in "cross flow experiments" [31] with a water recovery of 27 and $32 \%$ for the MB and MO experiments, respectively. Operating in the flow through mode and at the same flow rate $(1.5 \mathrm{ml} / \mathrm{min})$ would cause enhancement of the pressure above the operation limits of our photocatalytic membrane reactor (50bars).

When trying to evaluate the economic feasibility of the proposed hybrid photocatalytic/ultrafiltration water treatment process and compare it to the standard NF and RO processes, we should take into account both the energy consumed for powering the UV and Vis irradiation sources and the energy consumed by the pump to circulate the fluid into the reactor. As an example, applying three or more UVA light sources of $8 \mathrm{~W}$ each, with the purpose to achieve sufficient irradiation density on the $33 \mathrm{~cm}^{2}$ of active membrane surface had led to a total energy consumption which was identical to that required by a commercially available polymeric NF membrane process for treating the same amount of water. The reason is that photocatalytic membranes operate not only at much lower pressure but also at higher recovery (100\% compared to $30 \%$ ) [31] and as a consequence, they need less time to treat the same amount of water.

Furthermore, Figure 5 shows the amount of degraded pollutant (MO and MB) as a function of the energy spent by the process when applying the membrane $\mathrm{N}$ - 
$\mathrm{TiO}_{2}-10$. As seen, the UV light degradation of MB has an energy cost which is almost double compared to that of MO. Likewise, the Visible light degradation is 1.5 times more expensive when working with MB. In both cases the performance under visible light, is as good as that under UV light and even better for degraded amounts of MB up $0.08 \mathrm{mg}$. This proves that doping with Nitrogen activates successfully $\mathrm{TiO}_{2}$ in the Visible light part of the solar spectrum and the energy cost of employing external UV light sources, can be omitted.

\section{Conclusions}

Four types of titania mofified ultrafiltration membranes were produced via deposition and stabilization of novel photocatalytic materials on the external and internal (pore) surface of ceramic supports. All the membranes proved to be effective against common problems faced by the conventional high flux-thin film composite polymeric nanofiltration systems, when treating waste that contains textile dyes, like fouling tendency, increased energy consumption and the formation of hard-to-dispose toxic concentrate retendate effluents of the pollutant. All membranes performed better against $\mathrm{MB}$ than $\mathrm{MO}$. In particular, $\mathrm{N}-\mathrm{TiO}_{2}-10$ proved to be the best membrane for the treatment of MO under UV light and GOT-10 the most appropriate for the treatment of MB. The visible light activation attempts made toward reduction of the energy cost were successful. The proposed combined photocatalytic ultrafiltration process for organic load removal from water exploiting solar light as the only energy source, can be effectively applied as an energy efficient alternative to the typical nanofiltration process.

\section{Acknowledgements}

This research has been co-financed by the European Union (European Social Fund ESF) and Greek national funds through the Operational Program "Education and Lifelong Learning" of the National Strategic Reference Framework (NSRF) Research Funding Program: Thales "AOP-NanoMat" (MIS 379409). Financial support for this work was also provided by project PTDC/AAC-AMB/122312/2010 co-financed by FCT (Fundação para a Ciência e a Tecnologia) and FEDER (ERDF European Regional Development Fund) through Programme COMPETE (FCOMP01-0124-FEDER-019503). This work was also partially co-financed by FCT and 
FEDER through project PEst-C/EQB/LA0020/2013 (COMPETE). LMPM and SMT acknowledge financial support from FCT grants SFRH/BPD/88964/2012 and SFRH/BPD/74239/2010, respectively, and AMTS acknowledges the FCT Investigator 2013 Programme (IF/01501/2013), with financing from the European Social Fund and the Human Potential Operational Programme.

\section{References}

[1] H. Choi, K. Zhang, D.D. Dionysiou, D.B. Oerther, G.A. Sorial, J. Membr. Sci. 248 (2005) 189-199.

[2] S. Ciston, R.M. Lueptow, K.A. Gray, J. Membr. Sci. 342 (2009) 263-268.

[3] X.Sun, J. Zhang, G.Zhang, X.Pan, T.Huang, Catal Communs 18 (2012) 76-80.

[4] S. Mozia, A.W. Morawski, M. Toyodab, M. Inagakic. Sep and Purif Tech 63 (2008) 386-391.

[5] K. Nagaveni, G. Sivalingam, M.S. Hegde, G. Madras, Appl. Catal. B: Environ. 48 (2004) 83-93.

[6] V. Kandavelu, H.Kastien, K. Thampi Ravindranathan, Appl. Catal. B:Environ. 48 (2004) 101-111.

[7] N. L. Simantiris, , D. Riga, E. Katsivela, D. Mantzavinos, N.P. Xekoukoulotakis, Desalination 250 (2010) 351-355.

[8] R. Comparelli, E. Fanizza, M.L. Curri, P.D. Cozzoli, G. Mascolo, A. Agostiano, Appl. Catal. B: Environ. 60 (2005) 1-11.

[9] C. Guillard, H. Lachheb, A. Houas, M. Ksibi, E Elaloui, J.M. Herrmann, J Photochem Photobioy A: Chem 158 (2003) 27-36.

[10] S.-U. Geissen, W. Xi, A. Weidemeyer, A. Vogelpohl, L. Bousselmi, A. Ghrabi, A. Ennabli, Water Sci. Technol. 44 (2001) 245-249.

[11] Y.S. Lin, Sep. Purif. Technol. 25 (2001) 39-55.

[12] L.G.A. van de Water, T. Maschmeyer, Top. Catal. 29 (2004) 67-77.

[13] T.V. Gestel, C. Vandecasteele, A. Buekenhoudt, C. Dortemont, J. Luyten, R. Leysen, B.V.D. Bruggen, G. Maes, J. Membr. Sci. 207 (2002) 73-89.

[14] C.-Y. Tsai, S.-Y. Tam, Y. Lu, J. Brinker, J. Membr. Sci. 169 (2000) 255-268. 
[15] A.J. Burggraaf, L. Cot, General overview, trends and prospects, in: A.J. Burggraaf, L. Cot (Eds.), Fundamentals of Inorganic Membrane Science and Technology, Elsevier, Amsterdam, The Netherlands, 1996, 1-20

[16] A. Alem, H. Sarpoolaky, M. Keshmiri, J. Eur. Ceram. Soc. 29 (2009) 629-635.

[17] B.G.Kwon, J. Photochem. Photobio. A: Chem. 199 (2008) 112-118.

[18] M. Pelaez, N.T. Nolan, S.C. Pillai, M.K. Seery, P. Falaras, A.G. Kontos, P.S.M. Dunlop, J.W.J. Hamilton, J.A. Byrne, K. O’Shea, M.H. Entezari, D.D. Dionysiou, Applied Catalysis B: Environmental 125 (2012) 331-349.

[19] C. Han, M. Pelaez, V. Likodimos, A.G. Kontos, P. Falaras, K. O’Shea, D.D. Dionysiou, Appl. Catal. B: Environ. (2011) 107 77-87.

[20] N.G. Moustakas, A.G. Kontos, V. Likodimos, F. Katsaros, N. Boukos, D. Tsoutsou, A. Dimoulas, G.E. Romanos, D.D. Dionysiou, P. Falaras Applied Catalysis B: Environmental, 130-131 (2013) 14-24.

[21] L. M. Pastrana-Martínez, S.Morales-Torres, A. G. Kontos, N.G. Moustakas, J. L. Faria, J. M. Doña-Rodríguez, P. Falaras, A.M.T. Silva, Chem.Eng. J. 224 (2013) $17-$ 23.

[22] R. Leary, A. Westwood, Carbon 49 (2011), 741-772; L.M. Pastrana-Martínez , S. Morales-Torres, V. Likodimos, J.L. Figueiredo, J.L. Faria, P. Falaras, A.M.T. Silva, Appl. Catal. B: Environ., 123 (2012) 241-256.

[23] O.C. Vangeli, G.E. Romanos, K.G. Beltsios, D. Fokas, C.P. Athanasekou, N.K. Kanellopoulos, J. Mem. Sci. 365 (2010) 366-377.

[24] L.M. Pastrana-Martínez, S. Morales-Torres, V. Likodimos, J.L. Figueiredo, J.L.Faria, P. Falaras, A.M.T. Silva, Appl. Catal. B: Environ. (2012) 123, 241-256.

[25] W.S. Hummers, R.E. Offeman, J. Am. Chem. Soc. (1958) 80, 1339

[26] J. Araña, J.M. Doña-Rodríguez, D. Portillo-Carrizo, C. Fernández-Rodríguez, J. Pérez-Peña, O. González Díaz, J.A. Navío, M. Macías, Appl. Catal. B: Environ. 100 (2010) 346-354.

[27] L.M. Pastrana-Martínez, J.L. Faria, J.M. Doña-Rodríguez, C.FernándezRodríguez, A.M.T. Silva, Appl. Catal.B: Environ. (2012) 113-114, 221-227.

[28] G.Em. Romanos, C.P. Athanasekou, F.K. Katsaros, N.K. Kanellopoulos, D.D. Dionysiou, V. Likodimos, P. Falaras, Journal of Hazardous Materials 211- 212 (2012) 304- 316.

[29] P. Falaras, G. Romanos, P. Aloupogiannis, Photocatalytic Purification Device,European Patent, EP2409954 (A1) -2012-01-25, National Center for ScientificResearch Demokritos, Innovative Research \& Technology LTD. 
563

564

565

566

567

568

569
[30] H. Choi, M. G. Antoniou, M. Pelaez, A. A. De La Cruz, J. A. Shoemaker, D. D. Dionysiou, Environ. Sci. Technol. 41 (2007) 7530-7535.

[31] N.G. Moustakas, F.K. Katsaros, A.G. Kontos, G.Em. Romanos, D.D.

Dionysiou,P. Falaras, Catalysis Today 224 (2014) 56-69. 


\section{$570 \quad$ Figure Captions}

571 Figure 1: a) The adsorbed amount of pollutant $v s$. the total amount fed in the reactor

572 during dark experiments. b) The total amount of pollutant adsorbed on each

573 membrane in dark.

574 Figure 2: Molecular formulas of a) methylene blue b) methyl orange

575 Figure 3: Mass of pollutant consumed vs. total mass fed in the reactor a) MB and b)

$576 \quad \mathrm{MO}$

577 Figure 4: Mass of pollutant consumed vs. total mass fed in the reactor a) MB and b)

$578 \quad \mathrm{MO}$

579 Figure 5: Degraded pollutant mass by $\mathrm{N}-\mathrm{TiO}_{2}-10$ membrane, under irradiation vs the 580 corresponding energy consumption (shaft power of the pump) 
583 Table 1: Characteristic properties of the deposited photocatalysts versus the 584 photocatalytic efficiency of the membranes.

\begin{tabular}{|c|c|c|c|c|c|c|c|c|c|c|c|}
\hline & & & & \multicolumn{2}{|c|}{$\begin{array}{c}\text { Ads.amount } \\
(\mathrm{mg})\end{array}$} & \multicolumn{2}{|c|}{$\begin{array}{c}\text { Ads.capacity } \\
(\mathrm{mg} / \mathrm{g})\end{array}$} & \multicolumn{3}{|c|}{ Photocatalytic efficiency } \\
\hline & $\mathrm{pH}_{\mathrm{PZC}}$ & $\begin{array}{c}\mathrm{S}_{\mathrm{BET}} \\
\left(\mathrm{m}^{2} / \mathrm{g}\right)\end{array}$ & $\begin{array}{c}\text { Pore } \\
\text { vol. } \\
\mathrm{ml} / \mathrm{g}\end{array}$ & $\mathrm{MO}$ & $\mathrm{MB}$ & $\mathrm{MO}$ & $\mathrm{MB}$ & $\begin{array}{c}\text { MO- } \\
\text { UV }\end{array}$ & $\begin{array}{c}\text { MO- } \\
\text { Vis }\end{array}$ & $\begin{array}{c}\text { MB- } \\
\text { UV }\end{array}$ & $\begin{array}{c}\text { MB- } \\
\text { Vis }\end{array}$ \\
\hline $\begin{array}{c}\mathrm{N}- \\
\mathrm{TiO} 2- \\
10\end{array}$ & 6.7 & 175 & 0.46 & 0.41 & 0.28 & 2.8 & 0.73 & 0.212 & 0.133 & 0.347 & 0.252 \\
\hline ECT-10 & 5.2 & 18 & 0.25 & 0.195 & 0.34 & 7 & 1.56 & 0.062 & 0.045 & 0.28 & 0.111 \\
\hline GOT-10 & 3.2 & 110 & 0.17 & 0.15 & 0.22 & 5.13 & 1.12 & 0.065 & 0.041 & 0.248 & 0.153 \\
\hline $\begin{array}{c}\text { ref } \\
\text { GOT-10 }\end{array}$ & 3.5 & 120 & 0.11 & 0.059 & 0.11 & 3.6 & 0.65 & 0.049 & 0.019 & 0.095 & 0.0824 \\
\hline
\end{tabular}


Table 2: Flow and pressure conditions applied during the photocatalytic filtration experiments and performance characteristics of the developed membranes

$\begin{array}{lccc}\text { Rejection Permeance } & \text { Pressure } & \text { Membrane } \\ \text { Efficiency } & C / C_{0} & \text { Energy } \\ & \text { surface } & \text { consumption } \\ & \text { area } & \text { by the pump }\end{array}$

\begin{tabular}{|c|c|c|c|c|c|c|c|c|}
\hline & & & $R \%$ & $L m^{-2} h^{-1} b a r^{-1}$ & bar & $c m^{2}$ & & $\mathrm{kWh} / 100 \mathrm{~m}^{3}$ \\
\hline \multirow{6}{*}{$\frac{8}{8}$} & \multirow{3}{*}{$M B$} & dark & 11 & 17.3 & 1.7 & 29.6 & & 4.7 \\
\hline & & $U V$ & 36 & 21.2 & 1.5 & 30.4 & 0.65 & 4.2 \\
\hline & & Vis & 21 & 18.2 & 1.5 & 31.5 & 0.77 & 4.2 \\
\hline & \multirow{3}{*}{$M O$} & dark & 2 & 12.4 & 2.3 & 29.3 & & 6.3 \\
\hline & & $U V$ & 7 & 21.5 & 1.6 & 32.8 & 0.92 & 4.3 \\
\hline & & Vis & 5 & 17.6 & 1.8 & 31.5 & 0.94 & 5.1 \\
\hline \multirow{6}{*}{ 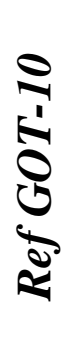 } & \multirow{3}{*}{$M B$} & dark & 13 & 20.5 & 1.4 & 27.0 & & 3.9 \\
\hline & & $U V$ & 14 & 32.9 & 1.3 & 25.1 & 0.86 & 3.7 \\
\hline & & Vis & 12 & 21.0 & 1.4 & 27.2 & 0.88 & 3.9 \\
\hline & \multirow{3}{*}{$M O$} & dark & 2 & 28.4 & 1.3 & 25.1 & & 3.5 \\
\hline & & $U V$ & 5 & 39.6 & 1.2 & 24.7 & 0.95 & 3.2 \\
\hline & & Vis & 2 & 31.7 & 1.1 & 26.5 & 0.98 & 3.2 \\
\hline \multirow{6}{*}{ 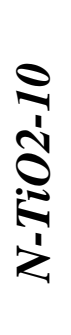 } & \multirow{3}{*}{$M B$} & dark & 9 & 5.5 & 5.2 & 30.8 & & 14.8 \\
\hline & & $U V$ & 57 & 8.3 & 4.6 & 30.6 & 0.82 & 14.6 \\
\hline & & Vis & 29 & 9.3 & 3.7 & 30.7 & 0.71 & 13.9 \\
\hline & \multirow{3}{*}{$M O$} & dark & 2 & 7.2 & 4.5 & 30.8 & & 12.6 \\
\hline & & $U V$ & 27 & 10.8 & 3.4 & 30.5 & 0.95 & 12.2 \\
\hline & & Vis & 15 & 11.6 & 2.8 & 30.6 & 0.97 & 11.7 \\
\hline \multirow{6}{*}{$\underset{v}{i}$} & \multirow{3}{*}{$M B$} & dark & 10 & 2.2 & 13.5 & 32.4 & & 37.7 \\
\hline & & $U V$ & 35 & 4.2 & 7.9 & 32.5 & 0.64 & 25.7 \\
\hline & & Vis & 22 & 3.8 & 8.4 & 32.3 & 0.84 & 22.9 \\
\hline & \multirow{3}{*}{$M O$} & dark & 2 & 2.8 & 10.3 & 32.5 & & 28.7 \\
\hline & & $U V$ & 7 & 4.7 & 8.1 & 33.0 & 0.93 & 27.0 \\
\hline & & Vis & 5 & 3.4 & 9.0 & 33.0 & 0.95 & 25.2 \\
\hline
\end{tabular}

590 


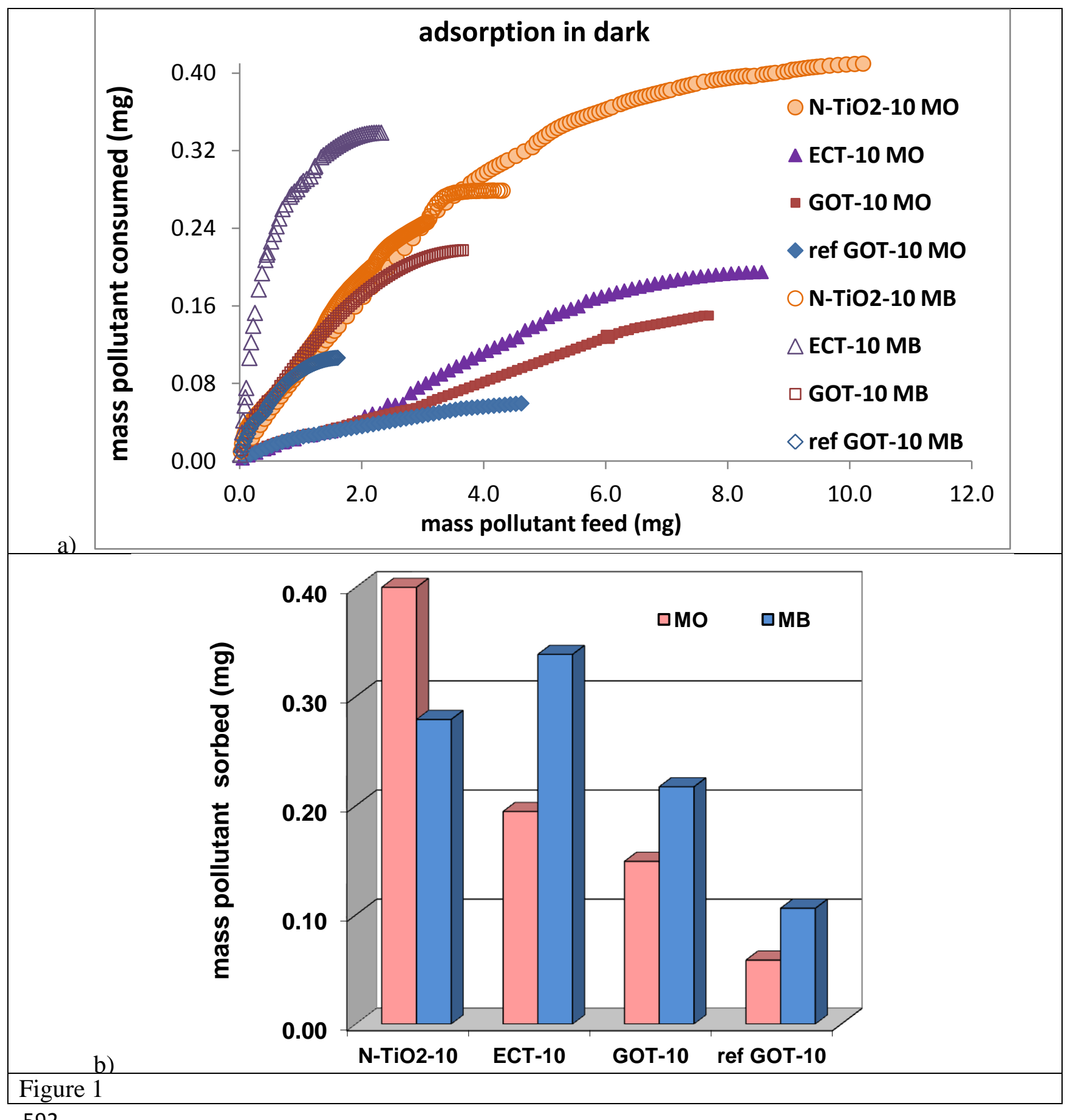

592

593 


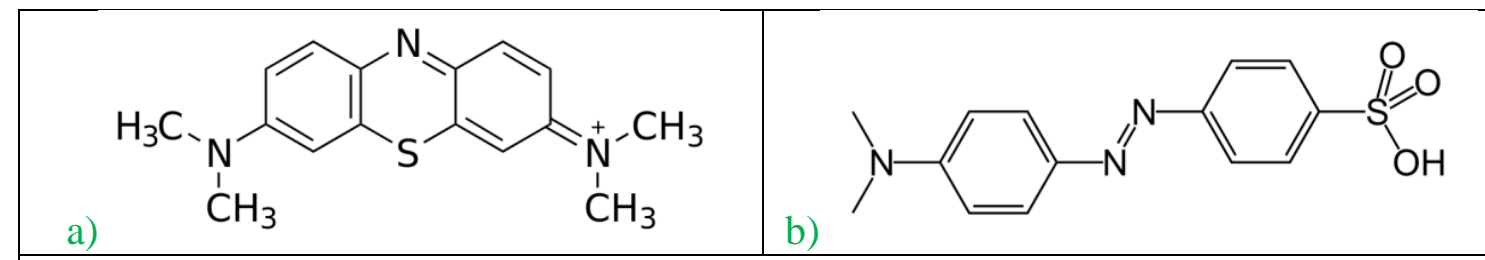

Figure 2

594

595 


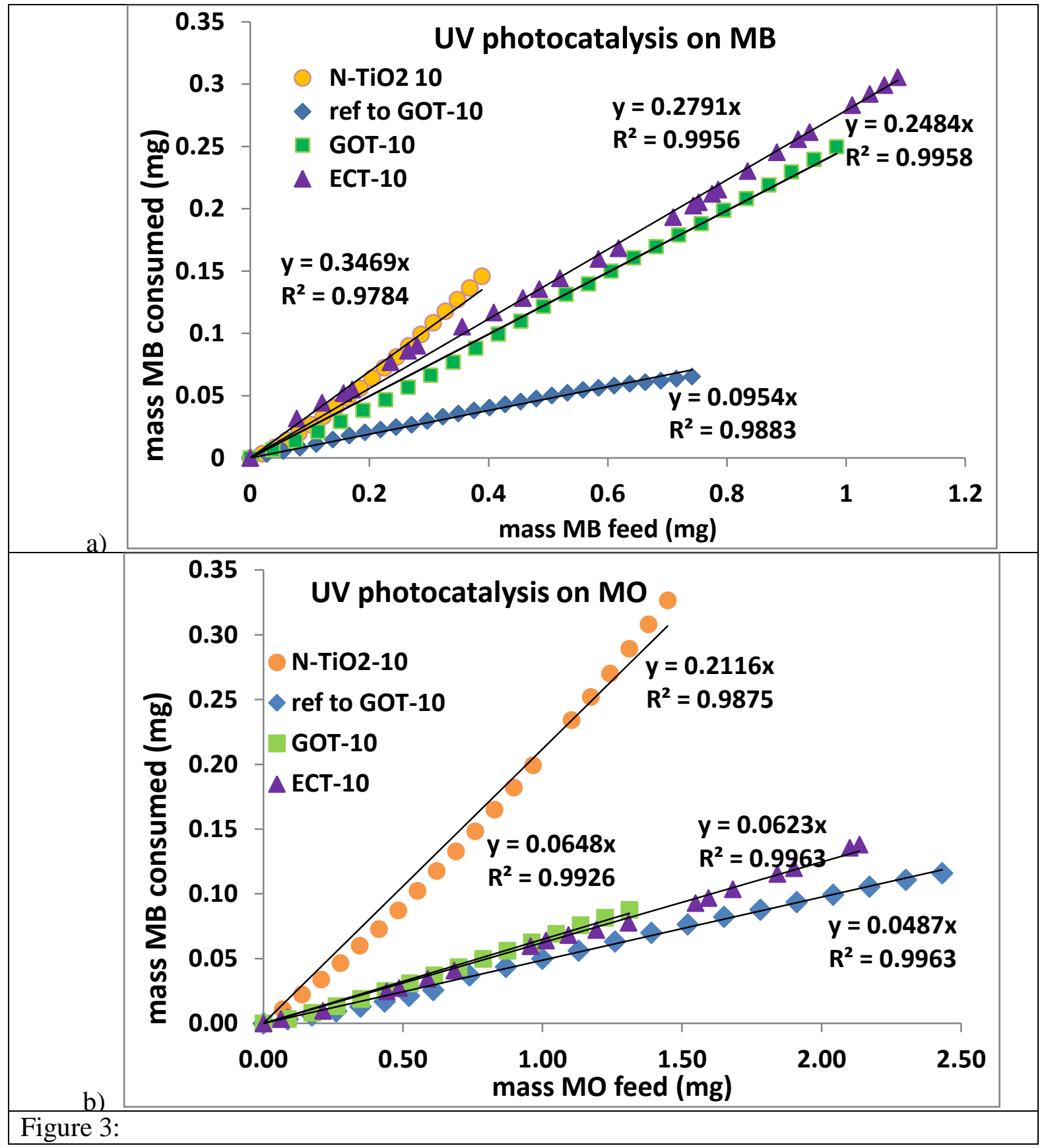

596

597 


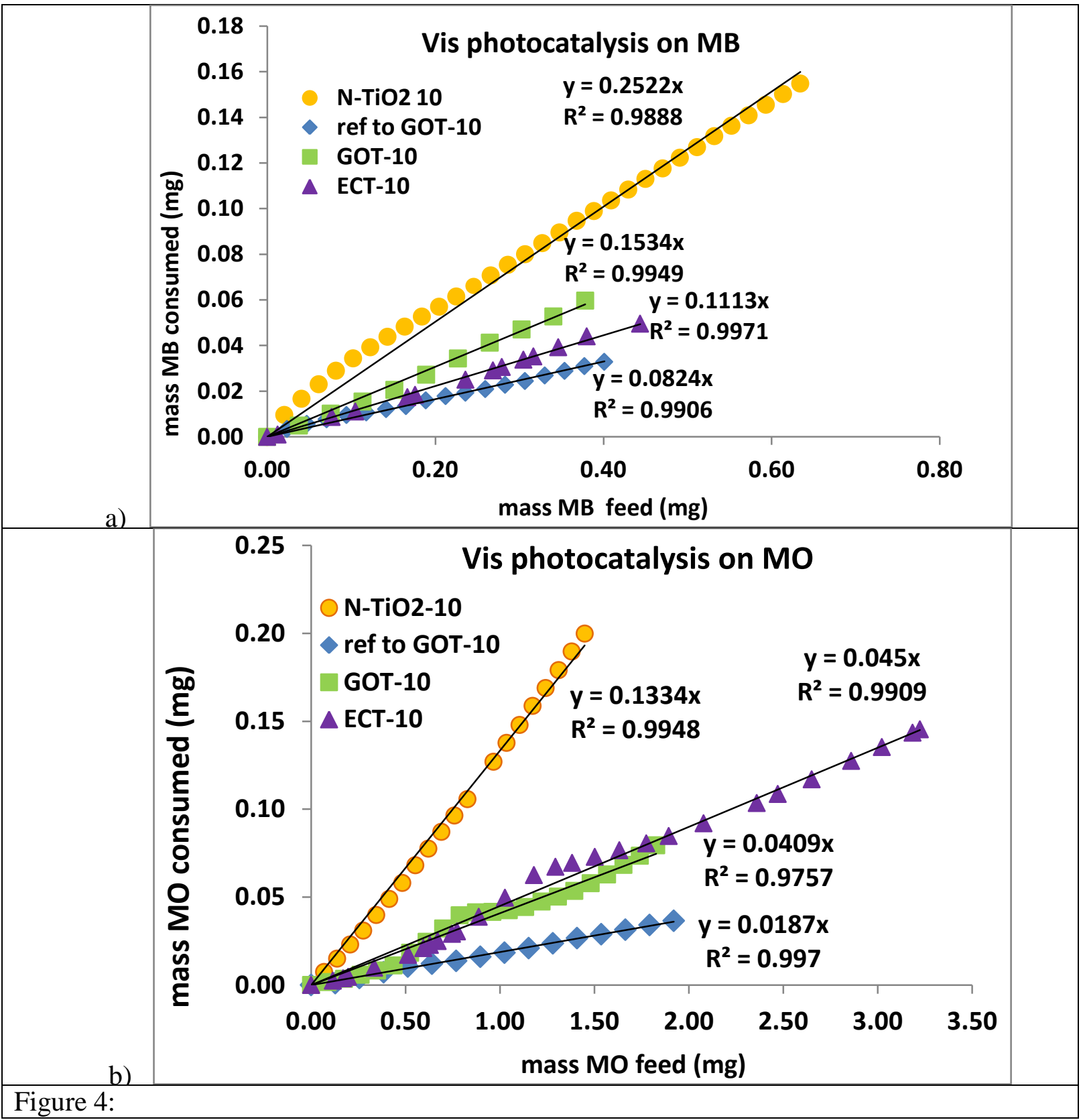

598 


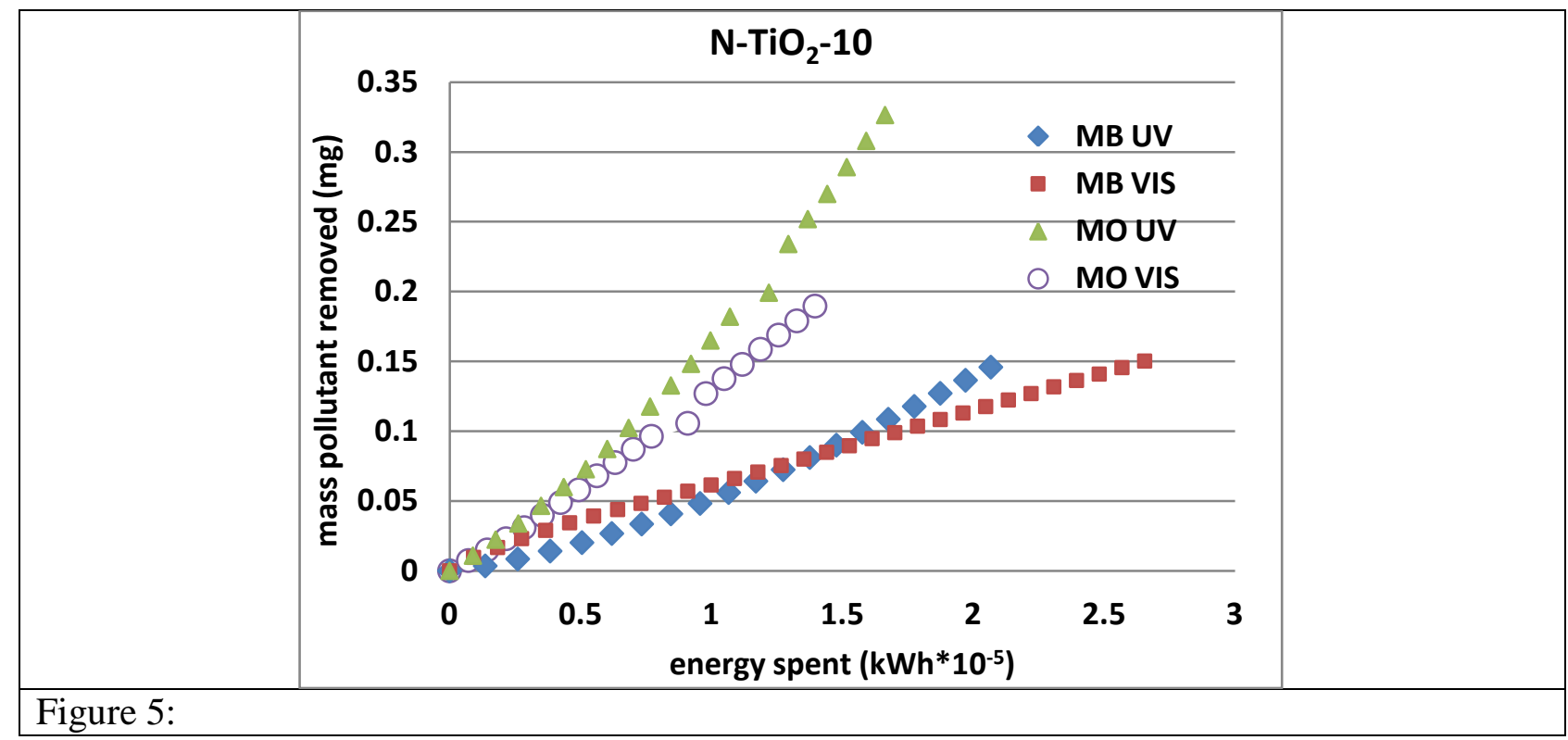

600 

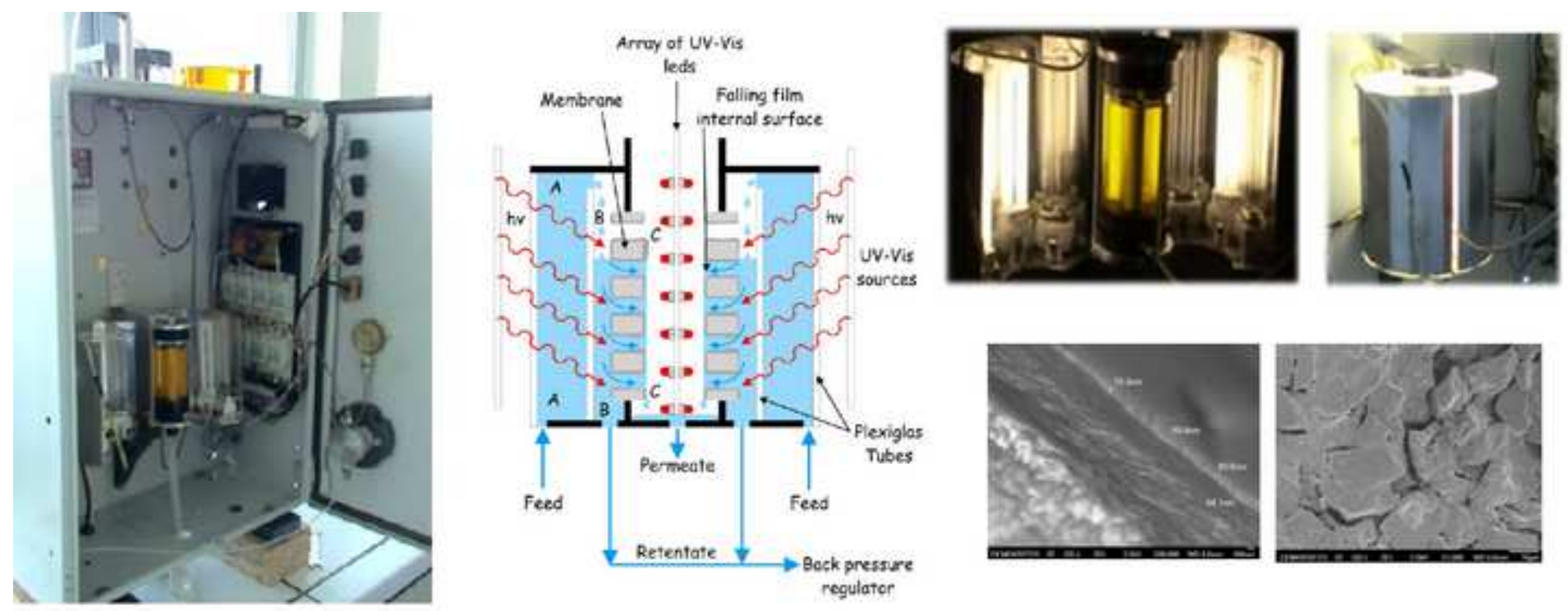

regulater 